\title{
Towards an Uncertainty Management Framework for Model-Based Definition and Enterprise
}

\author{
Kamran GOHER ${ }^{\mathrm{a}, 1}$, Essam SHEHAB ${ }^{\mathrm{b}}$, Ahmed AL-ASHAAB ${ }^{\mathrm{a}}$ and Shoaib SARFRAZ ${ }^{\mathrm{a}}$ \\ a Manufacturing Department, School of Aerospace, Transport and Manufacturing, \\ Cranfield University, Cranfield, Bedfordshire MK43 OAL, UK \\ ${ }^{\mathrm{b}}$ Mechanical and Aerospace Engineering Department, School of Engineering and \\ Digital Sciences, Nazarbayev University, Nur-Sultan 010000, Kazakhstan
}

\begin{abstract}
Globally the manufacturing industry is undergoing a shift in the way product specifications are defined, used, and re-used from conventional drawingbased systems to a comprehensive $3 \mathrm{D}$ digital product model. This transformation is at the heart of the digitization processes. The true benefits lie in the adoption of this technology throughout the product lifecycle. However, this digital transformation is partial and many of the stages in the product lifecycle are still heavily reliant on traditional drawings. This is due to the involvement of several uncertainties in the process of adoption of model-based definition. In this paper, a framework is proposed for the systematic assessment of the prevailing uncertainties in the adoption of model-based definition and enterprise. The framework proposed in this paper is aimed at identifying, categorizing, prioritizing, and mitigating the uncertainties in this process.
\end{abstract}

Keywords. Digital manufacturing, Uncertainties, Model-based definition, Modelbased enterprise.

\section{Introduction}

The conventional form of product definition had been the 2D drawings for a long period. The advancements in technology made it possible to present 3D models in place of conventional drawings. This 3D model was initially used for visualization of the product only while the authentic source for engineering activities remained the conventional drawing. Gradually the evolution in this process allowed embedding functional tolerance and annotations (FT\&A) to the 3D model and it started replacing 2D representation. This evolution continued with the introduction of semantic product manufacturing information (PMI) to the 3D model. This evolutionary advancement process aims to make this model a complete source of product information with semantic properties that can be used for all the lifecycle stages of the product. This leads to the digitization of the product definition, the realization of which is called a model-based definition.

Model-based definition (MBD) is a 3D model digital product model which is used as a single and complete source of product information instead of conventional drawings [1]. Model-based enterprise (MBE) adopts MBD for all the lifecycle of the product [2-

${ }^{1}$ Corresponding Author, Mail: K.Goher@cranfield.ac.uk 
4]. The high-value manufacturing industries like aerospace and automobile are ahead in this adoption. However, the journey towards MBE involves many challenges and uncertainties [5]. The previous researches had highlighted several uncertainties involved in this process. However, systematic work is needed to model these uncertainties from the perspective of risk and uncertainty management. This work addresses this gap by presenting the prevalent uncertainties in the adoption of MBD and proposing a methodology towards the development of a framework for the management of these uncertainties. The methodology involves using NUSAP pedigree assessment and Analytical Hierarchy Process (AHP).

\section{Uncertainty Management Framework}

In this study, the word "uncertainty management" has been used instead of "risk management" based on a concrete rationale. Firstly, the word "uncertainty" removes ambiguity related to the word "risk" which is a synonym of "threat" and "hazard". Secondly, uncertainty management unlike risk management provides a broader horizon for the identification of uncertainties in project management practices. Thirdly, uncertainty management focuses on managing the source of the threat instead of only the threat itself [6].

The process of risk and uncertainty management has been described by various resources presenting almost identical phases. These are plan, identity, analyze (qualitative and quantitative), respond (treat), and manage (monitor, control, record, and report) $[7,8]$. This framework involves three of these phases that are explained below.

\subsection{Identification}

The first phase in uncertainty management is the identification of the types of uncertainties and their categorization. The documentation of the list of uncertainties at an early stage is a baseline for uncertainty management. This can be carried out by many tools like literature review, brainstorming, checklists, surveys, interviews, root cause analysis, assumption, and constraint analysis, SWOT analysis, document analysis, prompt lists, and use of structured facilitation in meetings and workshops [7]. The application of a suitable tool depends upon the dynamics of the project which can vary from case to case. The result of this process is a list of uncertainties that contains a description of each uncertainty in the project. In this work literature review, brainstorming and interviews are used for the identification of the uncertainties.

\subsection{Assessment}

In the second phase of uncertainty management, assessment of the uncertainties is made for achieving the goal of prioritizing. To ensure the authenticity of this assessment, both qualitative and quantitative methods are applied. The qualitative assessment builds on the level of respondent approach in the understanding of each of the uncertainty. For this purpose, Pedigree Assessment is adopted. The quantitative assessment on the other hand is used to measure the weight of the uncertainty. For quantitative assessment, Analytical Hierarchy Process (AHP) is adopted in this project. The combination of these two assessments provides the relative significance of each uncertainty in the form of a rating. The outcome of this phase will be a classification of the identified uncertainties in low, 
medium, and high significance groups so that each of the uncertainty could be dealt with concerning its importance in the project.

\subsection{Response}

The third phase in this uncertainty management framework is the response to deal with the uncertainties. This phase is helpful for the decision-makers to handle both opportunities and threats by reducing threats and enhancing the opportunities [7]. This will result in a knowledge base for the mitigation of the uncertainties in the implementation of MBD within the organization. Figure 1 provides an overview of all these three phases which are being followed in pursuance of the development of the framework.

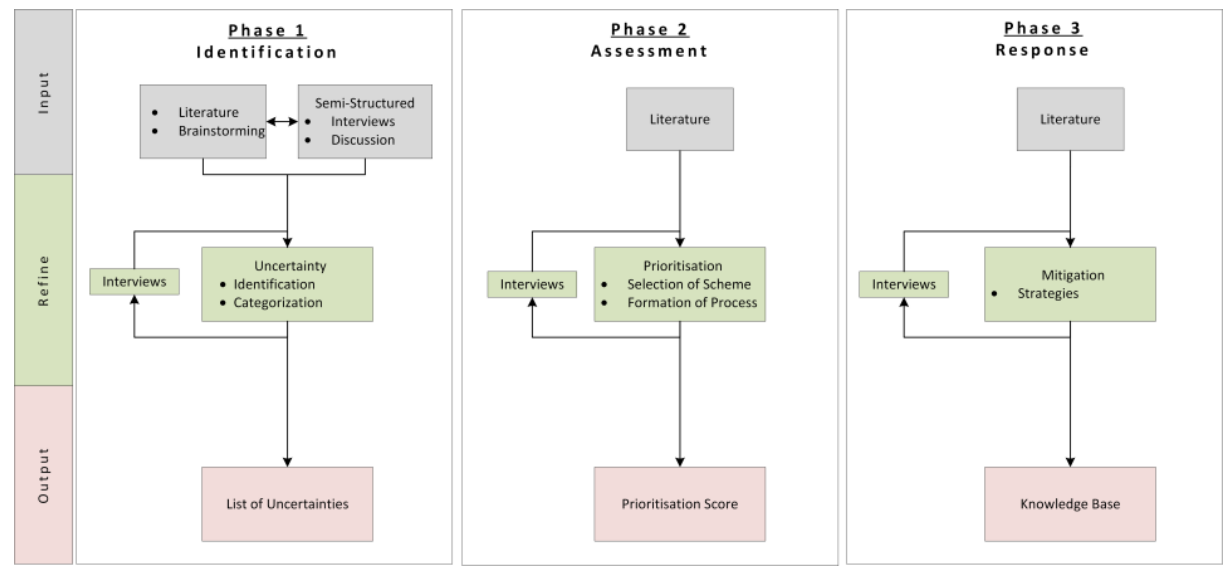

Figure 1: Phases for development of the framework

It is important to mention that this paper focuses on the first two phases of the framework. The response phase will be addressed later in the project. In the following section 2 , the identified uncertainties are presented (Phase 1). While Sections 3 and 4 respectively present the qualitative and quantitative assessment methods (Phase 2).

\section{Uncertainties in MBD}

In their previous work, the authors [4] have figured out the key issues and challenges associated with the adoption of model-based definition. After further literature study and critical brainstorming, an initial list of uncertainties is prepared and sorted out into five categories. This project is being carried out in collaboration with two renowned aerospace organizations. Semi-structured interviews were conducted with cross-domain experts within these organizations to refine the list of uncertainties. It is further extended to brainstorming sessions with the co-researchers in the digital manufacturing research group at Cranfield University. This refinement process resulted in the addition of a few uncertainties and removal of a some other which do not fulfill the definition of uncertainty. Additionally, the terminologies and definitions of prevailing uncertainties 
are modified to enhance generalization, practicality, and understanding. While determining these uncertainties following dimensions of the area are explored.

- Elements of MBD

- Software support

- Hardware support

- Cost of implementation

- Supplier readiness

- Data trust- Both user and certification perspectives

- Other digital data challenges

The list of the key uncertainties that have been determined during this research is presented in Table 1 with a short description of each.

Table 1: List of Uncertainties

\begin{tabular}{|c|c|c|}
\hline No. & Uncertainty Category & Uncertainty Type \\
\hline 1 & Technological Readiness & $\begin{array}{l}\text { - Software capabilities to meet the requirements of all lifecycle } \\
\text { - Stages } \\
\text { - Semantic PMI incorporation capability } \\
\text { - Semantic PMI consumption capability } \\
\text { - Interoperability between systems, data, languages, products, } \\
\text { and processes } \\
\text { - Hardware that supports MBD data } \\
\text { - Sow-cost hardware and software solutions for suppliers } \\
\text { - Interpretation of standards and PMI application techniques }\end{array}$ \\
\hline 2 & Managerial/Implementation & $\begin{array}{l}\text { - Legacy data shifting to MBD } \\
\text { - Vendor Lock-in } \\
\text { - Supplier readiness for MBD - Technology and manpower } \\
\text { capabilities } \\
\text { - Supplier MBD capability assessment criteria } \\
\text { - Absence of framework for evaluating benefits of MBD } \\
\text { adoption at different stages of the product lifecycle } \\
\text { - Clear MBE strategy (Phased/At-once) } \\
\text { - Framework/criteria for evaluation and selection of MBD } \\
\text { - software } \\
\text { - Ability to handle product complexity } \\
\text { - Change management strategies to suit modified workflows } \\
\text { - Training - Within organization and at supplier end }\end{array}$ \\
\hline 3 & Trustworthiness & $\begin{array}{l}\text { - Privacy, Confidentiality and Security of data } \\
\text { - Model Quality: Caused by an error from software user, poor } \\
\text { model development technique, CAD system, or translation } \\
\text { - Reliability - Fulfilment of all the requirements which were } \\
\text { available in the conventional form of product definition. } \\
\text { - Resilience - Formats that support technological advancements } \\
\text { which are fast and frequent }\end{array}$ \\
\hline
\end{tabular}




\begin{tabular}{|c|c|c|}
\hline No. & Uncertainty Category & Uncertainty Type \\
\hline 4 & Certification & $\begin{array}{l}\text { - Availability - Uncertainty in the availability of data over a } \\
\text { long period (Long Term Archival and Retrieval) } \\
\text { - Accessibility- Over a long period the software provider no } \\
\text { longer exists or if exist whether the current version supports } \\
\text { older data } \\
\text { - Interpretability - Lack of the capability of data format to be } \\
\text { interpretable by all versions of the software } \\
\text { - Integrity - Internal inconsistency or corruption of electronic } \\
\text { data } \\
\text { - Quality - Model data prone to quality defects cannot be } \\
\text { certified as master data }\end{array}$ \\
\hline 5 & Affordability & $\begin{array}{l}\text { - Supplier affordability } \\
\text { - Lack of cost-benefit analysis framework to plan adoption of } \\
\text { next level in MBE maturity } \\
\text { - Organization's own ability to spend on new technology }\end{array}$ \\
\hline
\end{tabular}

\section{The NUSAP System - Pedigree}

The available knowledge base for new technology adoption is usually a combination of fragmentary information, assumptions, domain-specific knowledge, and incomplete awareness of the technology and its application. This could result in incorrect assessments that do not represent the factual state. While modeling uncertainties, problem framing is a critical aspect and different views or opinions are needed to be oppugned and refined through value-laden assumptions. For this purpose, a notational system of assessment (NUSAP) has been proposed by Funtowicz and Ravetz [9]. It is composed of five qualifiers that encompass many angles associated with the understanding of uncertainties. It records both the quantitative and qualitative dimensions of the problem and facilitates communicating them in an unambiguous, standard way. Letter P denotes 'Pedigree' in this system.

Benefitting from this system, the pedigree assessment approach is adopted in this paper. Pedigree is an evaluation mechanism for the production of information. The benefit of its use is that it reduces arbitrariness and subjectivity of the judgment and thus improves the quality of information. Moreover, it can transform qualitative data into quantitative data.

It is composed of a set of criteria. The assessment involves a qualitative judgment of the expert against each criterion. A pedigree matrix is used for coding this qualitative judgment into a discrete numeral scale with the linguistic description of each level on the scale. The criteria and the description of each level can be tailored in the pedigree matrices to suit the type of information in the project [10].

The process of applying the pedigree approach involves four steps. [10]. Firstly, the researcher needs to know the subject matter under consideration for interviewing the expert. And the expert is needed to have access to the related material. Second, a structure of uncertainty for the project is needed to be set. Thirdly, the expert thinking process encompasses the knowledge of uncertainty under consideration. The final step is an encoding which describes quantitatively the expert belief over the uncertainty variable [11]. 
In this work, three criteria have been adopted for the pedigree assessment. Each criterion and its description for various levels are tailored to suit this research.

1. 'Basis of Estimate' refers to the availability of the relevant data and the experience of the expert in the area.

2. 'Rigor in assessment' refers to the method used to collect and analyze the data being used for the assessment.

3. 'Level of Validation' refers to the degree of effort to check the data against independent resources.

A scale comprising of values 1, 3, 5, and 7 is used for this assessment. The greater the value the greater would be the level of uncertainty. The description of each level in the three criteria is shown in Table 2.

Table 2: Pedigree Matrix

\begin{tabular}{llll}
\hline Score & Basis of Judgement & Rigour in Assessment & Level of Validation \\
\hline 1 & $\begin{array}{l}\text { Best possible data, Large } \\
\text { sample of data, Use of } \\
\text { historical data }\end{array}$ & $\begin{array}{l}\text { Best available practice in a } \\
\text { well-established discipline }\end{array}$ & $\begin{array}{l}\text { Best available, independent } \\
\text { validation within the domain, full } \\
\text { coverage of processes }\end{array}$ \\
\hline 3 & $\begin{array}{l}\text { Some experience in the } \\
\text { area, Small sample of } \\
\text { historical data, Internally } \\
\text { verified data }\end{array}$ & $\begin{array}{l}\text { Sufficiently experienced and } \\
\text { benchmarked internal process } \\
\text { with consensus on results }\end{array}$ & $\begin{array}{l}\text { Internally validated with sufficient } \\
\text { coverage of processes and verified } \\
\text { data, Limited independent } \\
\text { validation }\end{array}$ \\
\hline 5 & $\begin{array}{l}\text { An educated guess, Indirect } \\
\text { approximation, Rule of } \\
\text { thumb estimate }\end{array}$ & $\begin{array}{l}\text { Limited experience of process } \\
\text { with a lack of consensus on } \\
\text { results }\end{array}$ & $\begin{array}{l}\text { Limited internal validation, } \\
\text { No independent validation }\end{array}$ \\
\hline 7 & $\begin{array}{l}\text { No experience in the area, No discernable rigour } \\
\text { Speculation }\end{array}$ & No validation \\
\hline
\end{tabular}

For each of the uncertainty, the expert has to assess the source of his knowledge and score accordingly. The average assessed score of the three criteria will be used in the prioritization of the uncertainty in combination with the AHP assessment.

\section{Analytical Hierarchy Process}

For weighting the relative importance of uncertainties in terms of their significance, Analytical Hierarchy Process (AHP) is adopted. AHP is a popular and long-used multicriteria decision-making methodology [12]. It uses the approach of pairwise comparison between the decision criteria and thus makes it easy for the user to judge the criteria concerning their relative importance. The decision support methods are supposed to provide a trade-off between modeling and usability of the model. AHP fulfills this criterion well. Due to unambiguous methodology and ease of use, it has obtained wide acceptance among practitioners in addition to academia [13].

In AHP there is a goal, some decision criteria, and a set of alternatives for which decision is to be done [14]. The decision-maker uses pairwise comparison to give his opinion on his preference of the criteria using relative ratio scales [15]. For this comparison, Saaty has suggested a 9-point scale. These comparisons result in a 
comparison matrix. From this pairwise comparison matrix, the weight vector (w) is calculated based on Saaty's eigenvector procedure. This weight vector (w) provides the percentage relative significance of each of the criteria [16].

On the other end, the decision alternatives are judged by the experts who rank the alternatives against all the criteria set by the decision-makers. The same procedure of pairwise comparison and formation of a comparison matrix is repeated here to get the score matrix (S). Finally, the aggregation of both the processes i.e., for decision criteria and the decision alternatives, is done and the final result of this process is a ranking of the decision alternatives which takes into account both the decision-maker requirements and the expert judgment. This process is shown in Figure 2.

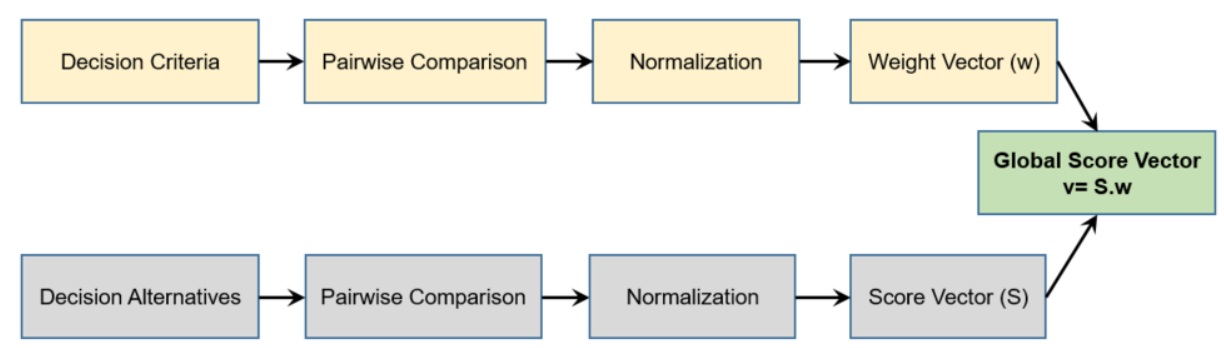

Figure 2. Analytical Hierarchy Process.

This framework involves AHP pairwise comparison of all the uncertainties to obtain weight vector $(\mathrm{w})$. The relative significance thus obtained will be used in combination with the average pedigree score from the previous section to obtain the overall relative significance of the uncertainty factors.

\section{Conclusions}

Model-based definition is the core of digital transformation for product data and an important enabler of smart factory and industry 4.0. Model-based enterprise provides a competitive advantage to manufacturing organizations by improving their processes. The manufacturing industry in general and high-value manufacturing in particular is adopting it at a rapid pace. But this adoption is partial. The uncertainties in the process of this adoption are the obstacles in the realization of a complete model-based enterprise.

The pedigree assessment provides a purifying method for any judgment. By scoring the quality of the judgment, it facilitates to increase the credibility of the uncertainty management process. AHP is a tested and long-used technique for weighing the relative importance of various criteria. The use of this method eases the process of uncertainty management in the framework. It facilitates the comparison process by providing a pairwise approach and at the same time converting the qualitative judgment into quantitative data.

This paper has presented a novel approach for uncertainty identification and assessment for MBD. This will provide a platform for the industry to assess the uncertainties involved and subsequently formalize effective MBE policy. This is an ongoing research project. The data collection is being carried out from academia and 
industry. Based on this framework a software tool is also being designed. This tool will facilitate industry and practitioners in setting an effective MBE organizational strategy.

Working on mitigation of each uncertainty presented in this work is a unique area of research, however, the next phase of this work will focus on exploring and presenting mitigation strategies for the most significant uncertainties. This will be followed by presenting a tool for the management of these uncertainties.

\section{References}

[1] V. Quintana, L. Rivest, R. Pellerin, F. Venne and F. Kheddouci, Will model-based definition replace engineering drawings throughout the product lifecycle? A global perspective from aerospace industry, Computers in Industry, 2010, Vol. 61, pp. 497-508.

[2] T. Hedberg, J. Lubell, L. Fischer, L. Maggiano and A.B. Feeney, Testing the digital thread in support of model-based manufacturing and inspection, Journal of Computing and Information Science in Engineering, 2016, Vol. 16, pp. 1-10.

[3] S.P. Frechette, Model based enterprise for manufacturing, In: 44th CIRP International Conference on Manufacturing Systems, Madison, 2011, pp. 1-6.

[4] K. Goher, E. Shehab and A. Al-Ashaab, Model-based definition and enterprise: State-of-the-art and future trends, Proceedings of the Institution of Mechanical Engineers, Part B: Journal of Engineering Manufacture, 2020, pp. 1-12.

[5] K. Goher, E. Shehab and A. Al-Ashaab, Challenges of Model-Based Definition for High-Value Manufacturing, In: 17th International Conference on Manufacturing Research, Belfast, 2019, pp. 22-27.

[6] S. Ward and C. Chapman, Transforming project risk management into project uncertainty management, International Journal of Project Management, 2003, Vol. 21, pp. 97-105.

[7] K.H. Rose, A Guide to the Project Management Body of Knowledge (PMBOK® Guide), Project Management Institute, Newtown Square, PA, USA, 2017.

[8] Risk management - Guidelines, ISO 31000, 2018.

[9] S.O. Funtowicz and J.R. Ravetz, Uncertainty and Quality in Science for Policy, Kluwer Academic Publishers, The Netherlands, 1990.

[10] J.P. Van Der Sluijs, M. Craye, S. Funtowicz, P. Kloprogge, J. Ravetz and J. Risbey, Combining quantitative and qualitative measures of uncertainty in model-based environmental assessment: The NUSAP system, Risk Analysis, 2005, Vol. 25, pp. 481-492.

[11] J.A. Erkoyuncu, R. Roy, E. Shehab and E. Kutsch, An innovative uncertainty management framework to support contracting for product-service availability, Journal of Service Management, 2014, Vol. 25, pp. 603-638.

[12] A. Ishizaka, Analytic Hierarchy Process and its Extensions, Springer, Cham, 2019.

[13] A. Ishizaka and A. Labib, Review of the main developments in the analytic hierarchy process, Expert Systems with Applications, 2011, Vol. 38, pp. 14336-14345.

[14] T.L. Saaty, Decision making with the analytic hierarchy process, International Journal of Services Sciences, 2008, Vol. 1, pp. 83-97.

[15] A. Ishizaka and A. Labib, Analytic hierarchy process and expert choice: Benefits and limitations, $O R$ Insight, 2019, Vol. 22, pp. 201-220.

[16] K. Goher, M. Jahanzaib, M.K. Ali, Consumer Preferences for Selection of Solar Home systems in Urban Areas, Pakistan, Mehran University Research Journal of Engineering and Technology, 2014, Vol. 33, pp. 441-448. 